\title{
Species, functional groups and community structure in seed banks of the arid Nama Karoo: Grazing impacts and implications for rangeland restoration
}

\author{
Niels Dreber ${ }^{\mathrm{a}, *}$, Jens Oldeland ${ }^{\mathrm{a}}$, Gretel M.W. van Rooyen ${ }^{\mathrm{b}}$ \\ a Biodiversity, Evolution and Ecology of Plants, Biocentre Klein Flottbek and Botanical Garden, University of Hamburg, Ohnhorststrasse 18, 22609 Hamburg, Germany \\ ${ }^{\mathrm{b}}$ Department of Plant Science, University of Pretoria, 0002 Pretoria, South Africa
}

\section{A R T I C L E I N F O}

\section{Article history:}

Received 13 November 2010

Received in revised form 31 March 2011

Accepted 3 April 2011

Available online $\mathrm{xxx}$

\section{Keywords:}

Degradation

Regeneration strategy

Restoration potential

Seed bank composition

Similarity pattern

Species abundance distribution

\begin{abstract}
A B S T R A C T
The regeneration potential of grazing-affected Nama Karoo vegetation was evaluated by comparing soil seed banks of different microsites across a fence-line contrast in arid Namibia. Seed banks under low and high grazing pressure reflected the condition of the standing vegetation in terms of composition, community structure and species abundance distributions. However, a close concordance between vegetation and seed bank was restricted to the herbaceous and grassy vegetation within the inter-shrub matrix.

The divergence of seed bank communities across the fence-line was low at community level but high at the level of species abundances. Continuous severe grazing increased the abundance of small-seeded, prostrate forbs with round seeds and favored unpalatable, annual grasses over palatable, perennial grasses. Microsites provided a source of small-scale variation in seed bank community composition and were dissimilar between the rangelands.

Results indicated an advanced divergence in the vegetation at the degraded site with seed banks of species common under sustainable grazing being drastically reduced. Their low abundance, even in safe sites, suggests that long-distance dispersal is one of the main limiting factors for natural re-establishment after disturbance. The inertia in recovery of Namibian degraded rangelands through seed limitation can be overcome only by active species introduction.
\end{abstract}

(C) 2011 Elsevier B.V. All rights reserved.

\section{Introduction}

The combination of heavy grazing and a highly variable climate has contributed to extensive environmental problems throughout southern Africa (Darkoh, 2009). In the arid Karoo, representing a significant proportion of the western part of South Africa and southern Namibia, degradation processes have been evident since the colonial occupation and the associated decrease of nomadic grazing and increase of livestock numbers in permanent settlements (Dean et al., 1995a). The reversibility of vegetation change is an important issue in these rangelands and a challenging task for land managers and restoration practitioners. There is a large body of literature on the dynamics and sustainable utilization of Karoo ecosystems (e.g. Beukes et al., 2002; Snyman, 1998; Todd and Hoffman, 2009) and the assessment of land degradation and restoration attempts (e.g. Dean et al., 1995b; Simons and Allsopp, 2007; Visser et al., 2004). However, the literature is dominated by studies focusing on aboveground assessments, often neglecting the role that soil seed banks play in ecosystem resistance and resilience. The assessment of soil

\footnotetext{
* Corresponding author. Tel.: +49 4042816 219; fax: +49 4042816539.

E-mail addresses: n.dreber@botanik.uni-hamburg.de, n.dreber@gmx.de (N. Dreber).
}

seed banks is widely accepted as a valuable tool to evaluate the condition and restoration potential of African rangelands (Jones and Esler, 2004; Kassahun et al., 2009; Snyman, 2004; Solomon et al., 2006) but to date regional studies from the arid south-western zone of Africa have overlooked this aspect for the most part. Thus, soil seed bank studies constitute a large gap in rangeland knowledge, particularly in the summer rainfall portion of the Karoo constituting the Nama Karoo Biome.

The effects of grazing on the structure of soil seed banks involve quantitative and compositional shifts of species and functional groups and changes in the relative importance of species-specific regeneration strategies (Aboling et al., 2008; Kinloch and Friedel, 2005a; Sternberg et al., 2003). These changes have important implications for the long-term sustainability of the rangeland with regard to the maintenance of regeneration capacity of vegetation, recovery potential of valuable fodder species and reversibility of community shifts. Cohorts of persistent seeds are able to stabilize populations through buffering disturbance effects by allowing for recruitment of suppressed species under favorable conditions. However, in the long-term, continuous disturbance (e.g. overgrazing) can lead to local extinction of plant species (O'Connor, 1991), and can result in almost irreversible changes in vegetation, whereby a return to previous conditions from the soil seed bank is prevented (Dutoit and Alard, 1995; Kinloch and Friedel, 2005a; 
Meissner and Facelli, 1999). Therefore, a key factor in sustainable resource management is resting, which might be more important than the way rangelands are utilized (Snyman, 1998). Nama Karoo rangelands can easily deteriorate if stocking rates do not accommodate the unpredictability of the seasonal climate. Many farmers apply a rotational grazing regime, which provides resting periods for the vegetation to recover and increases ecosystem resilience (Beukes et al., 2002; Domptail et al., 2010). Resting these rangelands in the wet season proved to be most effective (Müller et al., 2007), allowing plants to germinate, establish, flower and/or replenish the soil seed bank (Esler, 1999; O'Connor, 1991). However, such adapted management strategies rely on multi-camp grazing systems, which are common on privately owned, commercially farmed land, but absent in communal, open-access areas. This has contributed to widespread land degradation in the former homelands of Namibia (Klintenberg and Seely, 2004).

Comparative assessments of vegetation condition between adjacent communal and commercial farmlands in Namibia revealed changes in plant species composition, cover, diversity and production as a result of contrasting grazing regimes (Domptail et al., 2010; Kuiper and Meadows, 2002; Ward et al., 2000). Observed vegetation recovery in apparently deteriorated systems after good rainfall was seen as evidence for a high resilience of arid ecosystems in Namibia to heavy grazing pressure (Kuiper and Meadows, 2002; Ward et al., 1998). However, apparent vegetation recovery is also displayed by overgrazed, persistent vegetation assemblages with seed banks dominated by grazing-adapted annuals. Visual inspections are unable to provide adequate information on the nature of rangeland deterioration, i.e. whether it is permanent or short-term, and thus reversible, as they focus solely on structural properties (sensu López et al., 2011) of the ecosystem. Functional indicators related to recruitment processes, such as local seed reserves of key species, are necessary to estimate ecosystem resilience and to detect negative transitions in rangeland condition, which could cross a threshold beyond which active interventions becomes indispensable for rangeland improvement (Briske et al., 2008; López et al., 2011). We addressed the issue of soil seed banks as an indicator of rangeland condition and regeneration potential using a stable fence-line contrast between a highly degraded communal rangeland and an adjacent reference site in the arid Namibian Nama Karoo. As reviewed in Domptail et al. (2010), preceding investigations at the study sites provide interdisciplinary evidence for profound impacts on soils, hydrological processes, standing vegetation, and the local fauna that have been ascribed to continuous overstocking of the communal rangeland. Our study contributes to a more comprehensive understanding of the effects of unsustainable farming in arid Namibia by analyzing, for the first time, how high grazing pressure becomes manifested in soil seed banks.

The current study's aims were twofold. First, the objective was to determine the differential response of species and their abundances to contrasting grazing regimes, i.e. the magnitude of divergence of seed bank communities across the fence-line and its linkage to the standing vegetation. The following hypothesis was tested: long-term severe and continuous grazing has altered the community structure of the soil seed bank with directional selection being evident at the level of species, functional groups and regenerative traits, and, consequently, grazing-resistant annuals are favored leading to a higher similarity between vegetation and seed bank communities under high grazing pressure. Second, the study aimed to evaluate the capacity of current seed reserves of different microsites to contribute to an improvement of the degraded rangeland. As shrubs are known to function as effective seed traps and to provide safe sites for seedling establishment, the understorey seed bank composition can be expected to be more similar to communities of the non-degraded site

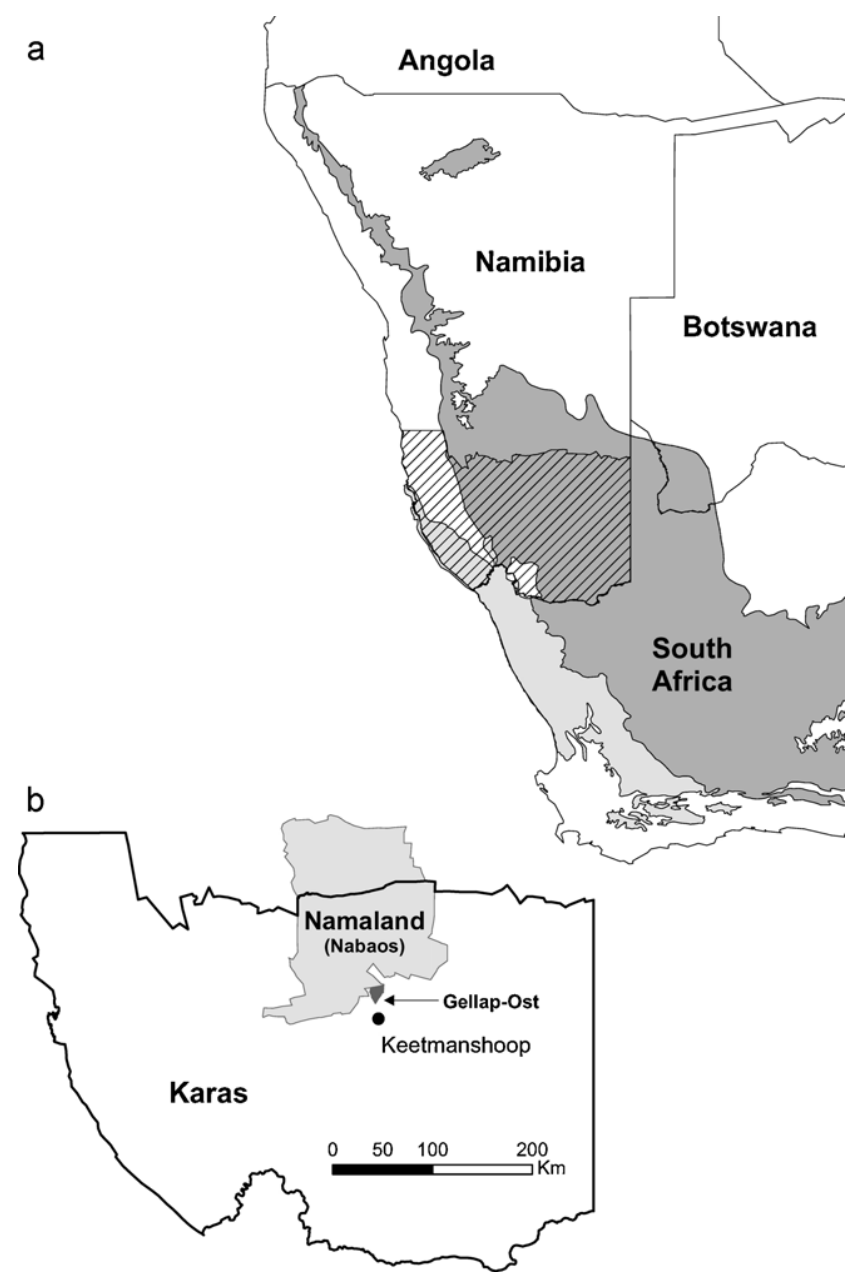

Fig. 1. (A) Geographic extent of the Karoo in south-western Africa including the summer-rainfall Nama Karoo Biome (dark gray) and the winter-rainfall Succulent Karoo Biome (light gray), and (B) location of the study sites in the Karas region of Namibia.

than the composition of seed pools of the exposed inter-shrub matrix.

\section{Materials and methods}

\subsection{Description of the study sites}

The study was carried out in Nama Karoo rangelands situated in the central Karas region of southern Namibia (Fig. 1). Climate is arid with an average annual summer rainfall of $150 \mathrm{~mm}$ and an inter-annual coefficient of variation of $70-80 \%$. The average annual water deficit, expressed as the difference between rainfall and rate of evaporation, exceeds $2500 \mathrm{~mm}$. Average maximum temperatures range from 34 to $36^{\circ} \mathrm{C}$ in January, minimum temperatures from 4 to $6^{\circ} \mathrm{C}$ in July (Mendelsohn et al., 2002). The area falls within the Namibian agro-ecological zone CPL7, which is characterized by an unreliable growing period, low biomass production and suitability for small stock farming only (Domptail et al., 2010). The adjacent study sites were located about $20 \mathrm{~km}$ north of the town of Keetmanshoop in two Biodiversity Observatories of the BIOTA Southern Africa project $\left(26^{\circ} 24.0717^{\prime} \mathrm{S}, 18^{\circ} 1.2905^{\prime} \mathrm{E}, 1100 \mathrm{~m}\right.$ a.s.l.). One site was situated in a 261 ha camp of the state research farm Gellap-Ost (Fig. 1), which has a history of sustainable grazing, with mainly sheep, for several decades. Due to a sophisticated management strategy, including rotational grazing and rangeland monitoring, low stocking densities, as well as the absence of eco- 
nomic incentives for profit maximization, rangelands of Gellap-Ost represent intact ecosystems in terms of biodiversity and ecosystem functioning (Domptail et al., 2010). This site served as a reference for natural grassy shrublands (hereafter referred to as REF). Separated by a fence, the second site, of approximately 3500 ha, is located directly adjacent to REF on the communal area of Nabaos, which forms part of the former Namaland homeland (Fig. 1). At this site, strong competition for resources and inappropriate governance structures have resulted in poor range management and high stocking densities. Severe and uncontrolled overgrazing by goats and free-roaming donkeys has contributed to a highly degraded state of the rangelands with vegetation transformed towards an open shrubland and prominent physical crusting of the soil surface (Domptail et al., 2010). Accordingly, this site is referred to as degraded (hereafter referred to as DEG).

The natural vegetation type as found on REF is typical for shale plains in the north-western, arid parts of the Nama Karoo Biome. The growth-form mix consists of scattered trees (Acacia spp., Maerua schinzii), tall woody shrubs such as Boscia foetida, Lycium spp. and Phaeoptilum spinosum, cover-dominant perennial grasses (Stipagrostis spp.), and annual herbs favored over perennial herbs (nomenclature following Germishuizen and Meyer, 2003). In contrast, the most prominent shrubs of DEG are Calicorema capitata and Rhigozum trichotomum. The inter-shrub matrix consists almost entirely of annual vegetation with a very few remnants of lean tussocks of perennial grasses. Most of the species, including the larger-seeded shrubs, possess at least short-term persistent seed banks (Dreber and Esler, 2011). According to Esler (1999), seed is the major regeneration strategy among Karoo species with very little reproduction by vegetative means. At the study sites, only the shrubs $R$. trichotomum and Catophractes alexandri are able to spread vegetatively to potentially produce free-living ramets. The dominating perennial grass Stipagrostis uniplumis has a dual strategy of population maintenance via both seed and vegetative buds but shows a greater resource allocation to seed reproduction (Hartnett et al., 2006).

\subsection{Seed bank sampling and emergence trials}

On both REF and DEG, three sampling areas 1 ha in size and of homogeneous vegetation were chosen. These corresponded to the long-term monitoring plots of the BIOTA Southern Africa project. Habitats were similar in geology (shale bedrock), soil type (sandyloamy Cambisols, clay content $<30 \%$, depth $>1 \mathrm{~m}$ ) and topography (plains, inclination 1-2\% NW). All sampling areas were at least $600 \mathrm{~m}$ away from the next water source for livestock, and from 200 to $500 \mathrm{~m}$ away from the bordering fence.

Soil was sampled in late January 2008 before the upcoming summer rains and any germination event. In order to identify spatial patterns in seed bank communities, different microsites were sampled: (i) shrub understoreys, termed 'canopy' (CAN), (ii) lowstature obstacles (OBS), and (iii) bare ground (BG). OBS included grass tussocks, surface rocks ( $>8 \mathrm{~cm}$ longest dimension), deadwood, and soil depressions. Per sampling area three $100 \mathrm{~m}$ transects running parallel to the topographic gradient were placed at random (nine per site). OBS and BG were sampled systematically and alternately along the transects at regular intervals of $10 \mathrm{~m}$ in $1-\mathrm{m}^{2}$ plots (Fig. 2). CAN was sampled under 10 shrubs of similar growth habit and size per sampling area. Due to this constraint the available number of shrubs per hectare did not allow for random selection of this microsite. Total sampling plots (i.e. $1-\mathrm{m}^{2}$ plots, shrubs) were $30 \times$ CAN, $45 \times$ OBS and $45 \times$ BG per study site. At each sampling plot, five replicate soil cores $(5.5 \mathrm{~cm}$ in diameter $\times 4 \mathrm{~cm}$ deep, total area sampled: $119 \mathrm{~cm}^{2}$ ) were taken and material pooled (total volume: $475 \mathrm{~cm}^{3}$ ). OBS samples were taken beside tussocks and rocks, beneath deadwood and/or in the centre of depressions. The number

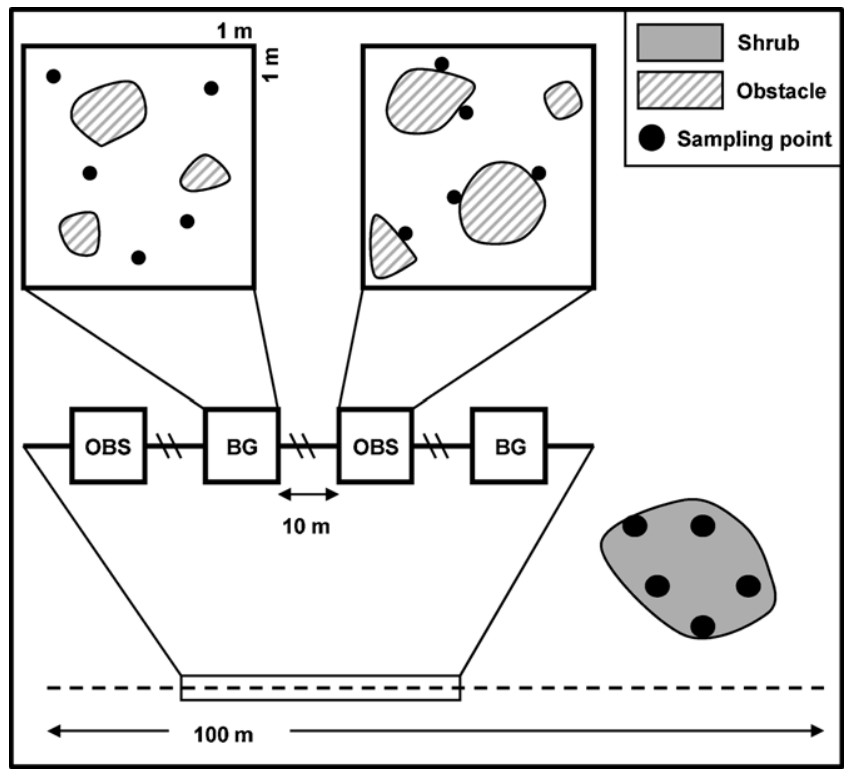

Fig. 2. Schematic representation of the sampling design, indicating a shrub (CAN microsite), 1 out of 3 (9) transects per sampling area (study site) with alternately positioned $1-\mathrm{m}^{2}$ sampling plots for obstacles (OBS) and bare ground (BG). Per sampling plot (1- $\left.\mathrm{m}^{2} \mathrm{plot} / \mathrm{shrub}\right)$ five replicate soil cores were taken and pooled.

of soil cores per type of obstacle was proportional to their presence in the sampling plot. Soil samples underneath shrubs were taken mid-way between shrub centre and canopy edge at regular intervals all around (Fig. 2). Compound samples per sampling plot were sieved to $2 \mathrm{~mm}$ to remove stones and coarse plant fragments. The remainder was screened for any seeds to be returned in the sieved material.

In the greenhouse, each compound sample was thoroughly stirred and spread out in four $9 \mathrm{~cm} \times 9 \mathrm{~cm}$ plastic trays on top of $5 \mathrm{~mm}$ of autoclave-sterilized sand covering a $70 \mathrm{~mm}$ deep layer of steam-sterilized sand-peat mix. The sand-peat mix was limed beforehand to a $\mathrm{pH}$ of $6.5-7.0$, similar to values measured in the field. Trays were placed at random and kept moist under controlled conditions, with a diurnal cycle of $14 \mathrm{~h}$ light at $30^{\circ} \mathrm{C}$ and $10 \mathrm{~h}$ darkness at $17^{\circ} \mathrm{C}$ for a total of five months. The number of emerged seedlings was counted daily and seedlings removed as soon as possible. For identification purposes, reference seedlings were replanted in separate trays until identification was possible. After 12 weeks, when germination rates approached zero, samples were stirred and germination trials continued until no new seedlings emerged for one week.

\subsection{Vegetation sampling}

In order to compare species composition and richness between the soil seed bank and standing vegetation, a species inventory of a $1000-\mathrm{m}^{2}$ plot in the centre of each 1 ha sampling area per study site was compiled. This approach assured that a representative sample of the standing vegetation was recorded, unlike $1-\mathrm{m}^{2}$ plot-based comparisons which would have missed many rare and scattered species and the tall shrubs. The comparison with the species inventory of the soil seed bank derived from samples collected in $1-\mathrm{m}^{2}$ plots distributed over the sampling area was deemed suitable because of the homogeneous nature of the vegetation at the $10000-\mathrm{m}^{2}$ scale. Data were collected in March 2008 at the peak of the growing season.

Species-specific abundance patterns in the vegetation and soil seed bank were compared by contrasting numbers of individuals per species derived from seedling counts in the greenhouse with 
in situ counts of plant individuals. For the latter, a $1-\mathrm{m}^{2}$ frame was thrown at random 10 times per sampling area into the field (total of 30 per study site), adjacent to the soil sampling plots. Individuals per species were counted within the north-westerly $0.25-\mathrm{m}^{2}$ quarter of the frame in February 2008. Due to the dense canopies of most shrubs, only the inter-shrub matrix was sampled for this purpose.

\subsection{Assessment of plant traits}

In order to identify grazing induced community shifts both in the vegetation and soil seed bank at the level of plant functional groups, vegetative traits and regenerative traits (sensu Cornelissen et al., 2003) for the most abundant species were used. Vegetative traits, predominantly associated with land use, included categorical data for growth form, growth habit and perenniality, which were based on field observations. Regenerative traits included diaspore mass, diaspore shape and dispersal mode. Measurements of diaspore attributes were carried out on the dispersule. Following Chambers et al. (1991), individual diaspore masses were obtained from 90 to 100 oven-dried $\left(48 \mathrm{~h}\right.$ at $\left.60^{\circ} \mathrm{C}\right)$ diaspores per species. Diaspore length-to-width ratio was calculated as a measure for shape (Navie and Rogers, 1997) with all appendages or enclosing structures which were assumed to be part of the dispersal unit entering the soil. Although dispersal of all recorded species can be regarded more or less restricted in space in time, lightweight diaspores $(<0.1 \mathrm{mg})$ and such with morphological characters directly interacting with dispersal agents like wind or animals (e.g. feathered awns, burs) were classified telechoric. All others were either classified antitelechoric (morphological characters hindering long-distance dispersal) or atelechoric (without telechory but not actually hindering it). Species were assigned the dispersal mode we judged to be predominant.

\subsection{Data analyses}

The linkage between the soil seed bank and standing vegetation was expressed as the closeness of similarity in species composition and species abundances. The floristic similarity between vegetation and seed bank communities was analyzed using the Sørensen index of similarity (Hopfensperger, 2007) based on total species counts per $1000-\mathrm{m}^{2}$ plot and species counts from all soil samples per hectare. Species abundance distributions (SADs) were used for visual and numerical comparisons of community patterns in the vegetation and soil seed bank per study site by means of rank abundance curves (Oldeland et al., 2010).

The magnitude of divergence of seed bank communities across the fence-line was determined at the level of species, functional groups and regenerative traits. Similarity in functional group composition of soil seed banks from REF and DEG was assessed by assigning species to a priori defined groups based on the vegetative traits. Group-differences in seed densities between the grazing regimes were tested by the assumption-free randomization t-test implemented in PAST v.1.99 (Hammer et al., 2001). Crossfence shifts in the abundance of regenerative traits as attributed to species were identified by reconciling the SADs. To determine the divergence of seed bank communities of REF and DEG and to test if shrubs at DEG increased the similarity of seed bank communities between grazing regimes, an analysis of similarity was used. In a first step, patterns in species assemblages among grazing regimes and microsites were assessed by non-metric multidimensional scaling (NMDS) based on a Bray-Curtis similarity matrix (Clarke, 1993). Stability of NMDS axes were assessed using a stress value which represents the match between observed and projected dissimilarities. Low stress values $(0.01-0.1)$ indicate a good representation of the observed reality. An ordination with three axes produced lowest overall stress values, hence a threedimensional NMDS was chosen. Abundance data from soil samples were square root-transformed to downweight the influence of dominating species. In order to achieve a better representation of species composition, samples from the same type of microsite per sampling area were pooled. This was necessary, as a high proportion of samples contained only a very few species, which is inappropriate when applying multivariate statistics. Moreover, NMDSs based on more than 100 samples are likely to reveal an unreliable pattern (Clarke, 1993). In a second step, significant differences in soil seed bank composition between the study sites and among microsites were identified by calculating dissimilarities between the groups of samples using the analysis of similarity (ANOSIM; see Clarke, 1993). This technique is free of distributional assumptions, and thus appropriate for analyzing community data based on highly skewed abundance data resulting from spatially clumped patterns in species distribution (Clarke, 1993), as in the case of soil seed banks. ANOSIM uses rank dissimilarities based on the Bray-Curtis coefficient of similarity, and, as a measure of how separated distinct groups are, calculates an $R$-statistic between one (groups are totally different) and zero (groups are indistinguishable). It should be noted that high $R$-values can appear to be non-significant or low $R$-values significant if ANOSIM is based on only a few replicates, and thus permutations in calculation (Clarke and Gorley, 2006). In a last step, similarity percentage analysis (SIMPER; see Clarke, 1993) was performed to identify species responsible for sample groupings by NMDS and group differences given by ANOSIM, respectively. All analyses were conducted using the software PAST v.1.99 (Hammer et al., 2001).

\section{Results}

\subsection{Overall seed bank composition and size}

In total, 6673 seedlings germinated from the soil seed bank comprising 45 taxa (REF: 32, DEG: 36, 23 in common), of which 40 were identified at least to genus level (Table 1 ). The total seed density of identified species was 1390 seeds $\mathrm{m}^{-2}$ at REF and 3050 seeds $\mathrm{m}^{-2}$ at DEG. Independent of the grazing regime, the belowground species composition was dominated by forbs with most (94.4\%) of the seed that germinated from annual species (REF: $89.9 \%$, DEG: $96.4 \%$ ). Understorey seed banks (CAN) were most diverse and comprised highest seed densities, whereas soil seed banks of bare ground (BG) contained the lowest number of species and seeds. At DEG, each type of microsite contained more than twice as many seeds as the respective microsite at REF, whereas total species richness was similar (Table 2).

\subsection{Divergence of seed bank communities across the fence-line}

Upon comparing REF and DEG plant functional groups were represented by similar proportions of the species spectrum of the seed banks (Fig. 3A-a), but they differed in the relative frequencies of seed densities (Fig. 3A-b). There was a profound shift from the dominance of upright forbs under sustainable grazing ( $81 \%$ of total germination at REF; Fig. 3A-b) towards the dominance of prostrate forbs under high grazing pressure ( $72 \%$ of total germination; Fig. 3A-b) and a significant reduction $(p<0.001)$ of the seed bank of perennial grasses (proportion of total germination: $R E F=7 \%$, DEG $=0.2 \%$; Fig. 3A-b).

Species of the inter-shrub matrix, which had highest seed numbers in the soil under low grazing pressure, were less abundant both in the vegetation and soil seed bank at DEG and vice versa (Table 3 ). Abundance patterns of regenerative traits showed no clear pattern. Under both grazing regimes, over-represented species (ranks 
Table 1

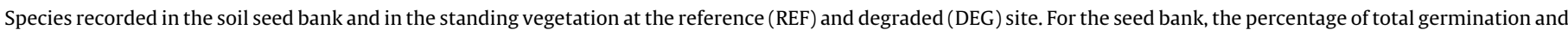

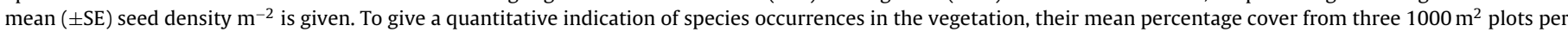

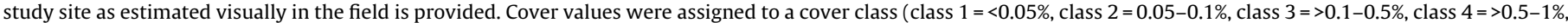
class $5=>1-5 \%$, class $6=>5 \%$ ).

\begin{tabular}{|c|c|c|c|c|c|c|}
\hline \multirow[t]{3}{*}{ Species } & \multicolumn{4}{|l|}{ Soil seed bank } & \multicolumn{2}{|c|}{ Standing vegetation } \\
\hline & \multicolumn{2}{|l|}{ REF } & \multicolumn{2}{|l|}{ DEG } & \multirow{2}{*}{$\begin{array}{l}\text { REF } \\
\text { Cover class }\end{array}$} & \multirow{2}{*}{$\begin{array}{l}\text { DEG } \\
\text { Cover class }\end{array}$} \\
\hline & $\%$ of germination & Seed density (seeds $\mathrm{m}^{-2}$ ) & $\%$ of germination & Seed density (seeds $\mathrm{m}^{-2}$ ) & & \\
\hline \multicolumn{7}{|l|}{ Forbs } \\
\hline Aizoanthemum dinteri & & & & & & 1 \\
\hline Amaranthus praetermissus & 11.98 & $166.6 \pm 59.7$ & 5.30 & $161.7 \pm 43.9$ & 1 & 2 \\
\hline Anticharis senegalensis & 0.05 & $0.7 \pm 0.7$ & 0.02 & $0.7 \pm 0.7$ & 1 & \\
\hline Boerhavia repens & & & 0.18 & $5.6 \pm 2.1$ & & 3 \\
\hline Chamaesyce glanduligera & 0.15 & $2.1 \pm 1.5$ & 0.11 & $3.5 \pm 1.5$ & 1 & 1 \\
\hline Chascanum pinnatifidum & & & & & 1 & \\
\hline Cullen obtusifolia & & & & & 1 & 1 \\
\hline Dicoma capensis & 2.30 & $31.9 \pm 4.9$ & 0.11 & $3.5 \pm 1.5$ & & \\
\hline Dicoma schinzii & & & & & & 1 \\
\hline Forsskaolea viridis & & & & & & 1 \\
\hline Gisekia africana & 0.60 & $8.3 \pm 3.5$ & & & 3 & \\
\hline Helichrysum candolleanum & 35.45 & $492.9 \pm 39.3$ & 10.09 & $308.2 \pm 30.3$ & 1 & \\
\hline Indigastrum argyroides & 0.15 & $2.1 \pm 1.2$ & 30.69 & $937.1 \pm 64.4$ & & 6 \\
\hline Indigofera auricoma & & & & & & 1 \\
\hline Indigofera charleriana & & & & & 1 & \\
\hline Indigofera sp. & 0.15 & $2.1 \pm 1.5$ & & & & \\
\hline Jamesbrittenia fragilis & & & 0.02 & $0.7 \pm 0.7$ & & \\
\hline Kissenia capensis & & & & & 1 & \\
\hline Kohautia caespitosa & 0.30 & $4.2 \pm 1.7$ & 1.36 & $41.7 \pm 6.9$ & 1 & 1 \\
\hline Laggera decurrens & 0.10 & $1.4 \pm 1.0$ & 0.07 & $2.1 \pm 1.2$ & & \\
\hline Limeum argute-carinatum & 0.30 & $4.2 \pm 1.7$ & 0.39 & $11.8 \pm 2.8$ & 3 & 3 \\
\hline Limeum rhombifolium & & & & & & 1 \\
\hline Lotononis platycarpa & 13.98 & $194.4 \pm 47.5$ & 0.05 & $1.4 \pm 1.0$ & 5 & 1 \\
\hline Microcharis disjuncta & 13.88 & $193.0 \pm 23.2$ & 0.11 & $3.5 \pm 1.5$ & 5 & \\
\hline Mollugo cerviana & 0.70 & $9.7 \pm 3.3$ & 0.39 & $11.8 \pm 3.3$ & 1 & 1 \\
\hline Monsonia umbellata & & & & & 2 & \\
\hline Myxopappus hereroensis & 0.15 & $2.1 \pm 1.2$ & 0.52 & $16.0 \pm 4.4$ & & \\
\hline Phyllanthus pentandrus & 0.75 & $10.4 \pm 9.7$ & & & & \\
\hline Sesamum triphyllum & & & & & 1 & 1 \\
\hline Tephrosia dregeana & 1.05 & $14.6 \pm 4.0$ & 1.41 & $43.0 \pm 11.6$ & 3 & 3 \\
\hline Trianthema parvifolia & 0.20 & $2.8 \pm 1.4$ & 40.87 & $1248.1 \pm 95.4$ & & 6 \\
\hline Tribulus pterophorus & & & & & 1 & 2 \\
\hline Tribulus terrestris & & & & & & 1 \\
\hline Tripteris microcarpa & 0.15 & $2.1 \pm 1.5$ & & & 1 & \\
\hline \multicolumn{7}{|l|}{ (Dwarf) Shrubs, trees } \\
\hline Acacia mellifera & & & & & & 1 \\
\hline Acacia nebrownii & & & & & 1 & 1 \\
\hline Aptosimum spinescens & & & & & 1 & \\
\hline Asparagus sp. & & & & & 1 & \\
\hline Blepharis obmitrata & & & & & 5 & \\
\hline Boscia foetida & & & & & 3 & 1 \\
\hline Cadaba aphylla & & & & & 3 & 1 \\
\hline Calicorema capitata & 1.95 & $27.1 \pm 23.1$ & 2.96 & $90.2 \pm 16.8$ & 1 & 4 \\
\hline Catophractes alexandri & & & & & 3 & \\
\hline Hermannia fruticulosa & & & 0.05 & $1.4 \pm 1.0$ & & \\
\hline Hermannia modesta & & & 0.02 & $0.7 \pm 0.7$ & 1 & 1 \\
\hline Hibiscus elliottiae & & & & & 1 & \\
\hline Hoodia sp. & & & 0.02 & $0.7 \pm 0.7$ & & \\
\hline Indigofera pechuelii & & & & & 1 & \\
\hline Leucosphaera bainesii & & & & & 1 & 1 \\
\hline Limeum aethiopicum & & & & & 1 & \\
\hline Lophiocarpus polystachyus & & & & & & 1 \\
\hline Lycium sp. & & & 0.05 & $1.4 \pm 1.0$ & & 1 \\
\hline Monechma genistifolium & 0.05 & $0.7 \pm 0.7$ & 0.02 & $0.7 \pm 0.7$ & 1 & 3 \\
\hline Peliostomum leucorrhizum & & & & & & 1 \\
\hline Phaeoptilum spinosum & 1.25 & $17.4 \pm 5.9$ & 0.23 & $6.9 \pm 2.7$ & 4 & \\
\hline Ptycholobium biflorum & & & & & 1 & \\
\hline Rhigozum trichotomum & & & 0.05 & $1.4 \pm 1.0$ & & 4 \\
\hline Salsola sp. & & & & & & 1 \\
\hline Sericocoma heterochiton & & & & & 1 & \\
\hline Sisyndite spartea & & & & & & 1 \\
\hline Solanum dinteri & 0.1 & $1.4 \pm 1.0$ & & & 1 & 1 \\
\hline Tetragonia schenckii & & & & & 1 & 1 \\
\hline Wellstedia dinteri & & & & & 1 & \\
\hline \multicolumn{7}{|l|}{ Grasses } \\
\hline Aristida adscensionis & 0.10 & $1.4 \pm 1.0$ & 2.82 & $86.1 \pm 16.5$ & 1 & 2 \\
\hline Chloris virgata & & & 0.07 & $2.1 \pm 1.2$ & & \\
\hline
\end{tabular}


Table 1 (Continued)

\begin{tabular}{|c|c|c|c|c|c|c|}
\hline \multirow[t]{3}{*}{ Species } & \multicolumn{4}{|l|}{ Soil seed bank } & \multicolumn{2}{|c|}{ Standing vegetation } \\
\hline & \multicolumn{2}{|l|}{ REF } & \multicolumn{2}{|l|}{ DEG } & \multirow{2}{*}{$\begin{array}{l}\text { REF } \\
\text { Cover class }\end{array}$} & \multirow{2}{*}{$\begin{array}{l}\text { DEG } \\
\text { Cover class }\end{array}$} \\
\hline & $\%$ of germination & Seed density (seeds $\mathrm{m}^{-2}$ ) & $\%$ of germination & Seed density (seeds $\mathrm{m}^{-2}$ ) & & \\
\hline Enneapogon cenchroides & 0.05 & $0.7 \pm 0.7$ & & & 1 & \\
\hline Enneapogon desvauxii & 0.05 & $0.7 \pm 0.7$ & 0.05 & $1.4 \pm 1.0$ & & 1 \\
\hline Eragrostis biflora & 1.25 & $17.4 \pm 13.5$ & & & & \\
\hline Eragrostis porosa & & & 0.02 & $0.7 \pm 0.7$ & & \\
\hline Schmidtia kalahariensis & 0.30 & $4.2 \pm 2.2$ & 1.43 & $43.7 \pm 9.4$ & 1 & 4 \\
\hline Setaria verticillata & 5.69 & $79.1 \pm 40.5$ & 0.25 & $7.6 \pm 7.6$ & 1 & 1 \\
\hline Stipagrostis hirtigluma & & & & & & 1 \\
\hline Stipagrostis hochstetteriana & 0.90 & $12.5 \pm 3.8$ & & & 5 & 1 \\
\hline Stipagrostis uniplumis & 5.89 & $81.9 \pm 9.2$ & 0.16 & $4.9 \pm 1.8$ & 6 & 1 \\
\hline
\end{tabular}

1-3) were mainly atelechoric with small and rounded diaspores. Among the species of intermediate abundance ( $>10$ seeds; REF: rank 4-7, DEG: rank 4-10), medium sized and wind dispersed diaspores seemed to be favored at REF, and oblong and/or tiny, partly epizoochorous diaspores at DEG (Table 3).
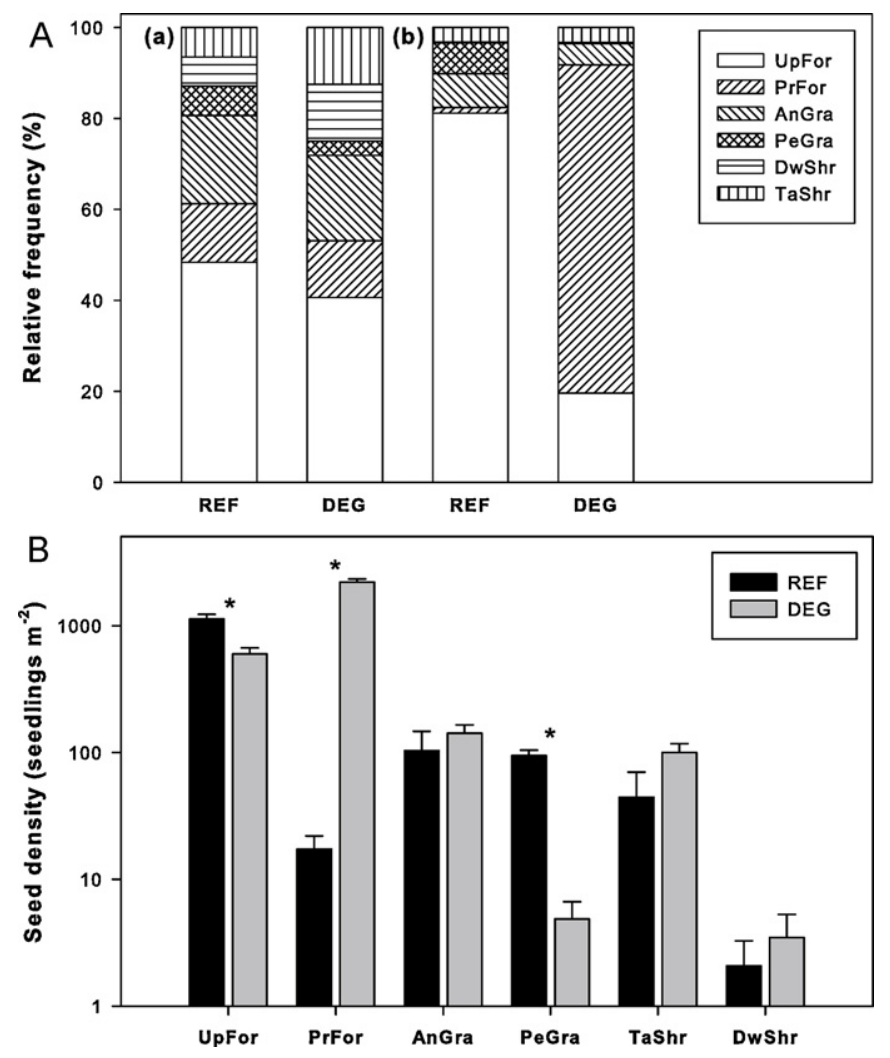

Fig. 3. Distribution of plant functional groups in response to the grazing regime (data from all microsites pooled). (A) Relative frequency of functional groups expressed as (a) a percentage of total seed bank species richness and (b) a percentage of total germination by study site. (B) Seed densities per functional group (bars with SE). * Indicates significant differences between grazing regimes at $p<0.001$. $\mathrm{REF}=$ reference site, $\mathrm{DEG}=$ degraded site, AnGra = annual grasses, DwShr $=$ dwarf shrubs, PeGra = perennial grasses, PrFor = prostrate forbs, TaShr = tall shrubs and UpFor $=$ upright forbs.
The NMDS ordination indicated a clear separation of seed bank communities between REF and DEG (Fig. 4A). This pattern was supported by ANOSIM results indicating a significant dissimilarity in seed bank species composition between the study sites $(R=0.99$, $p<0.001)$. As calculated by SIMPER, only twelve species contributed $80 \%$ to the total dissimilarity between REF and DEG. Two prostrate annual species, Trianthema parvifolia and Indigastrum argyroides, accounted for most of the dissimilarity (Table 4). While barely present at REF, these species dominated the soil seed bank at DEG with the highest mean seed densities among all species across the study sites (Table 1). Further discriminating species for DEG were the annual grass Aristida adscensionis and the shrub C. capitata. Despite their abundance under high grazing pressure and rare occurrence at REF (Table 1 ), their mean percentage contribution to the overall dissimilarity was low (Table 4). In contrast, two upright forbs (Microcharis disjuncta and Lotononis platycarpa) and a perennial grass ( $S$. uniplumis) were characteristic for the soil seed bank of REF (Table 4). Together with Helichrysum candolleanum, both forbs constituted a dominant seed bank fraction at REF, while $S$. uniplumis was the most abundant grass species in the seed bank of REF (Table 1). Each of the three species made up less than $0.2 \%$ of total germination from samples collected at DEG (Table 1 ).

\subsection{Spatial patterns in seed bank communities}

At REF, CAN seed banks from the three sampling sites were heterogeneous in species composition forming, nevertheless, a distinct cluster in ordination space. Species assemblages of inter-shrub microsites were less clearly distinguished with NMDS indicating some overlap along axis 1 and 2 between OBS and BG (Fig. 4C). The overall dissimilarity of microsites at REF was significant (ANOSIM: global $R=0.64, p=0.003$ ). Open-matrix seed banks were barely separable (ANOSIM: OBS vs. BG: $R=0.11, p=0.395$ ), whereas CAN seed banks were most discrete (ANOSIM: CAN vs. OBS: $R=0.85, p=0.095$ CAN vs. BG: $R=0.93, p=0.1)$. At DEG, all microsites were well separated in ordination space with high within-microsite variation (Fig. 4D). The overall dissimilarity of microsites at DEG was significant (ANOSIM: global $R=0.95, p=0.003$ ), and post hoc comparisons of groups supported the clustering by NMDS (ANOSIM: CAN vs. OBS: $R=1, p=0.103$; CAN vs. BG: $R=1, p=0.102$; OBS vs. $\mathrm{BG}: R=0.93$, $p=0.096$ ).

Table 2

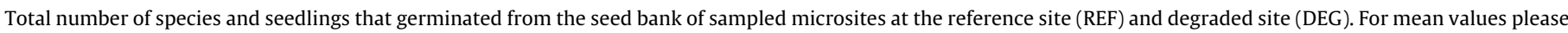
refer to Dreber and Esler (2011).

\begin{tabular}{|c|c|c|c|c|c|c|}
\hline & \multicolumn{2}{|c|}{ Canopy (CAN) } & \multicolumn{2}{|c|}{ Obstacle (OBS) } & \multicolumn{2}{|c|}{ Bare ground (BG) } \\
\hline & REF & DEG & REF & DEG & REF & DEG \\
\hline Total species richness & 28 & 29 & 20 & 23 & 14 & 15 \\
\hline Total germination & 889 & 1856 & 808 & 1803 & 396 & 921 \\
\hline
\end{tabular}




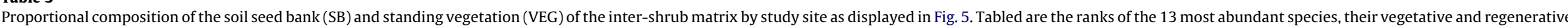
traits. $\mathrm{REF}=$ reference site, $\mathrm{DEG}=$ degraded site, $\mathrm{L} / \mathrm{W}=$ length-to-width-ratio.

\begin{tabular}{|c|c|c|c|c|c|c|c|c|c|c|c|c|}
\hline \multirow[t]{2}{*}{ Species } & \multicolumn{2}{|c|}{ REF rank } & \multicolumn{2}{|c|}{ DEG rank } & \multicolumn{3}{|l|}{ Plant traits } & \multicolumn{3}{|l|}{ Diaspore traits } & \multicolumn{2}{|l|}{ Dispersal } \\
\hline & SB & VEG & SB & VEG & $\begin{array}{l}\text { Growth } \\
\text { form }\end{array}$ & Perenniality & $\begin{array}{l}\text { Growth } \\
\text { habit }\end{array}$ & $\mathrm{L} / \mathrm{W}($ mean $\pm \mathrm{SE})$ & Shape $^{\mathrm{a}}$ & $\operatorname{Size}^{\mathrm{b}}\left(\right.$ mean mass $\left.\mathrm{mg}^{-1}\right)$ & Mode $^{c}$ & Category \\
\hline Helichrysum candolleanum & 1 & 13 & 3 & 5 & Forb & Annual-biennial & Upright & - & Oblong & - & Wind $^{1}$ & Telechory \\
\hline Lotononis platycarpa & 2 & 2 & & & Forb & Annual & Upright & $1.15 \pm 0.02$ & Rounded & Small (0.54) & Unassisted & Atelechory \\
\hline Microcharis disjuncta & 3 & 1 & & 13 & Forb & Annual & Upright & $1.13 \pm 0.02$ & Rounded & Small (0.41) & Self $^{2}$ & Atelechory \\
\hline Stipagrostis uniplumis & 4 & 4 & 12 & & Grass & Perennial & Upright & $26.04 \pm 1.78$ & Elongated & Small (0.42) & Wind $^{1,3}$ & Antitelechory \\
\hline Dicoma capensis & 5 & 3 & & 11 & Forb & Annual-biennial & Upright & $1.27 \pm 0.06$ & Rounded & Medium (1.94) & Wind $^{1}$ & Telechory \\
\hline Stipagrostis hochstetteriana & 6 & 11 & & & Grass & Perennial & Upright & $9.02 \pm 0.25$ & Elongated & Medium (4.97) & Wind ${ }^{1,3}$ & Antitelechory \\
\hline Tephrosia dregeana & 7 & 6 & 4 & 4 & Forb & Annual-biennial & Upright & $1.56 \pm 0.04$ & Oblong & Large (5.50) & Self $^{2}$ & Atelechory \\
\hline Mollugo cerviana & 8 & 12 & 10 & 8 & Forb & Annual & Upright & $1.12 \pm 0.03$ & Rounded & Tiny $(0.04)$ & Unassisted & Telechory \\
\hline Amaranthus praetermissus & 9 & & 7 & & Forb & Annual & Upright & $1.04 \pm 0.01$ & Rounded & Small (0.40) & Unassisted & Atelechory \\
\hline Calicorema capitata & 10 & & 9 & & Tall shrub & Perennial & Upright & $1.64 \pm 0.03$ & Oblong & Large (7.83) & Wind $^{1}$ & Telechory \\
\hline Kohautia caespitosa & 11 & & 6 & 7 & Forb & Annual & Upright & $1.63 \pm 0.03$ & Oblong & Tiny $(0.07)$ & Unassisted & Telechory \\
\hline Gisekia africana & 12 & 8 & & & Forb & Annual & Prostrate & $1.18 \pm 0.02$ & Rounded & Tiny $(0.24)$ & Unassisted & Atelechory \\
\hline Phaeoptilum spinosum & 13 & & & & Tall shrub & Perennial & Upright & $1.09 \pm 0.02$ & Rounded & Large (49.37) & Wind $^{4}$ & Telechory \\
\hline Limeum argute-carinatum & & 5 & 11 & 3 & Forb & Annual & Prostrate & $1.13 \pm 0.01$ & Rounded & Small $(0.70)$ & Unassisted & Atelechory \\
\hline Blepharis obmitrata & & 7 & & & $\begin{array}{l}\text { Dwarf } \\
\text { shrub }\end{array}$ & Annual-biennial & Upright & - & Oblong & - & Water $^{5}$ & Antitelechory \\
\hline Monsonia umbellata & & 9 & & & Forb & Annual & Upright & $2.84 \pm 0.06$ & Oblong & Medium (3.55) & Wind $^{1,3}$ & Antitelechory \\
\hline Chamaesyce glanduligera & & 10 & & 12 & Forb & Annual & Upright & $1.71 \pm 0.03$ & Oblong & Medium (0.92) & Ant $^{6}$ & Telechory \\
\hline Trianthema parvifolia & & & 1 & 2 & Forb & Annual & Prostrate & $1.06 \pm 0.01$ & Rounded & Tiny $(0.17)$ & Unassisted & Atelechory \\
\hline Indigastrum argyroides & & & 2 & 1 & Forb & Annual & Prostrate & $1.16 \pm 0.02$ & Rounded & Small (0.59) & Unassisted & Atelechory \\
\hline Aristida adscensionis & & & 5 & 6 & Grass & Annual & Upright & $1.93 \pm 0.15$ & Oblong & Small (0.67) & Animal $^{7}$, wind ${ }^{1}$ & Telechory \\
\hline Schmidtia kalahariensis & & & 8 & 9 & Grass & Annual & Upright & $1.85 \pm 0.07$ & Oblong & Small (0.63) & Animal $^{7}$, wind ${ }^{1}$ & Telechory \\
\hline Boerhavia repens & & & 13 & 10 & Forb & Annual & Prostrate & $2.26 \pm 0.06$ & Oblong & Medium (2.75) & Unassisted & Atelechory \\
\hline
\end{tabular}

a Shape categories following Navie and Rogers (1997): rounded $\leq 1.5$, oblong $=1.5-3$ and elongated $>3$.

b Size categories as in Dreber and Esler (2011): tiny $=<0.3 \mathrm{mg}$, small $=0.3-0.9 \mathrm{mg}$, medium $=1-5 \mathrm{mg}$ and large $=>5 \mathrm{mg}$

c Dispersal mode/mechanism: ${ }^{1}$ anemochory, ${ }^{2}$ autochory, ${ }^{3}$ trypanospermy, ${ }^{4}$ anemochoric synaptospermy, ${ }^{5}$ hygrochasy, ${ }^{6}$ myrmecochory, and ${ }^{7}$ epizoochory. 

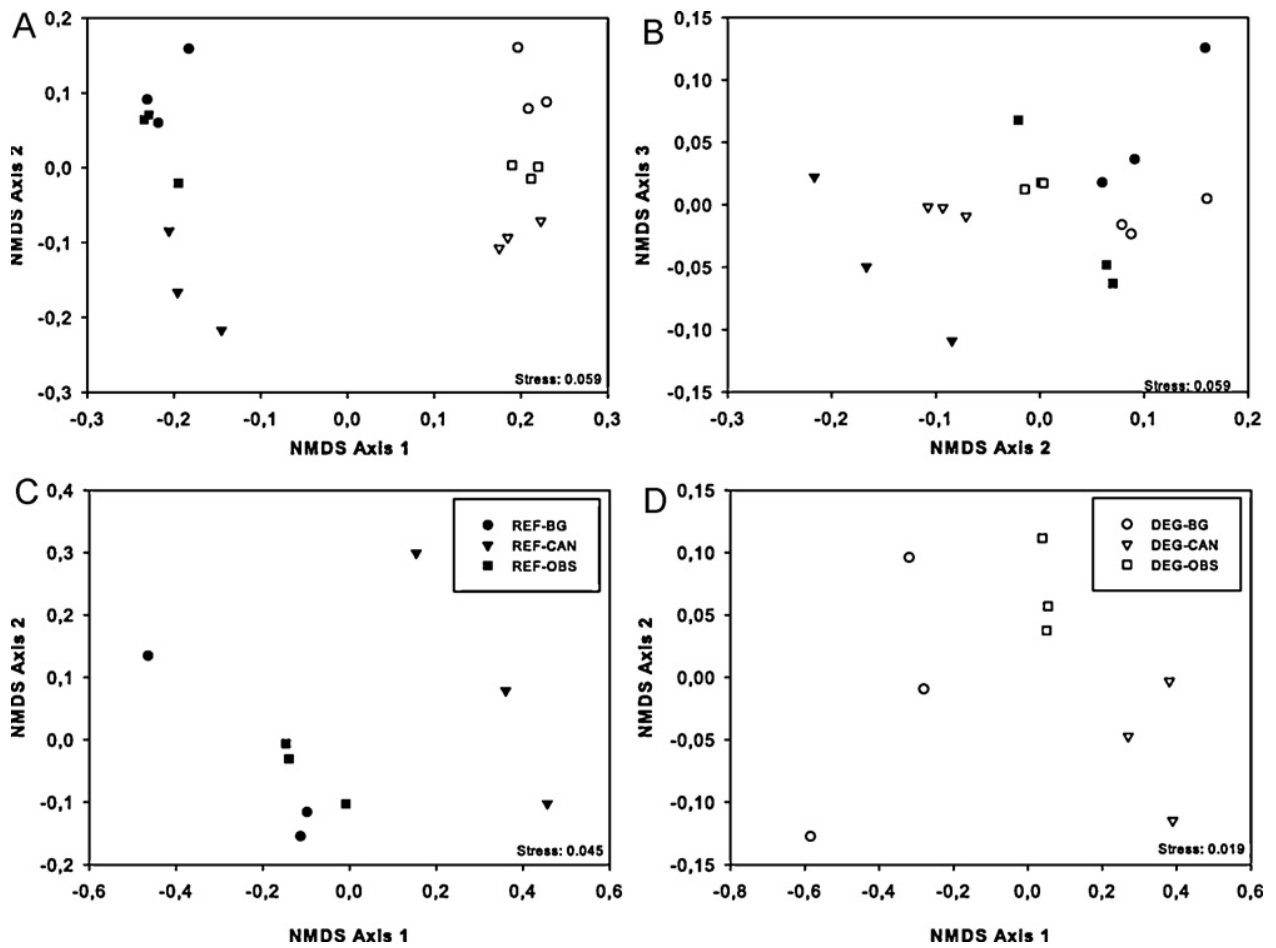

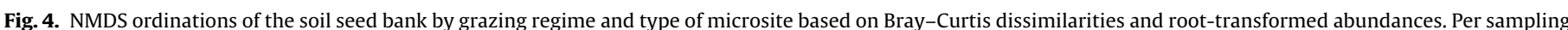

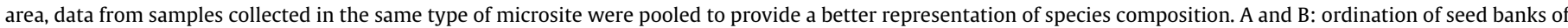
REF and DEG (symbols according to legend in C and D); C: seed bank of REF; D: seed bank of DEG. REF = reference site and DEG = degraded site.

\section{Table 4}

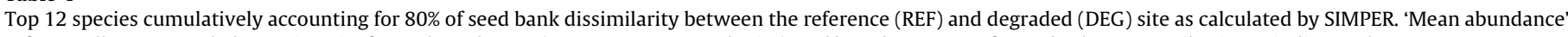

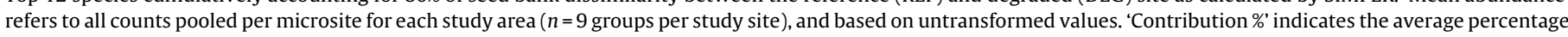

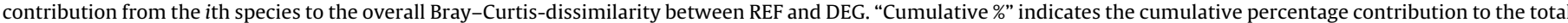
dissimilarity (tabled is a cut-off of $80 \%$ for the total of 40 identified species germinated in the greenhouse).

\begin{tabular}{|c|c|c|c|c|}
\hline \multirow[t]{2}{*}{ Species } & \multicolumn{2}{|c|}{ Mean abundance } & \multirow[t]{2}{*}{ Contribution (\%) } & \multirow[t]{2}{*}{ Cumulative (\%) } \\
\hline & REF & DEG & & \\
\hline Trianthema parvifolia & 0.4 & 200.0 & 14.0 & 20.0 \\
\hline Indigastrum argyroides & 0.3 & 150.0 & 12.0 & 37.1 \\
\hline Microcharis disjuncta & 30.9 & 0.6 & 4.9 & 44.1 \\
\hline Lotononis platycarpa & 31.1 & 0.2 & 4.8 & 50.9 \\
\hline Amaranthus praetermissus & 26.7 & 25.9 & 3.7 & 56.2 \\
\hline Stipagrostis uniplumis & 13.1 & 0.8 & 3.1 & 60.7 \\
\hline Aristida adscensionis & 0.2 & 13.8 & 2.8 & 64.7 \\
\hline Calicorema capitata & 4.3 & 14.4 & 2.6 & 68.3 \\
\hline Helichrysum candolleanum & 78.9 & 49.3 & 2.4 & 71.8 \\
\hline Kohautia caespitosa & 0.7 & 6.7 & 1.9 & 74.5 \\
\hline Dicoma capensis & 5.1 & 0.6 & 1.8 & 77.2 \\
\hline Schmidtia kalahariensis & 0.7 & 7.0 & 1.8 & 79.7 \\
\hline
\end{tabular}

Results of ANOSIM confirmed an overall high dissimilarity between the microsites sampled at REF and DEG (global $R=0.87, p=0.001$ ). Rotating sample-pools in NMDS ordinationspace revealed some degree of similarity between the same types of microsites across the fence-line, as indicated by the microsite sequence canopy-obstacle-bare ground along the second NMDS axis (Fig. 4B). This was also implied by the lowest mean dissimilarities calculated by SIMPER for respective group comparisons, even though not that striking (Table 5). However, as indicated by the post hoc $R$-statistics of group comparisons (Table 5), species assemblages of all microsites were still well separated across the fence-line.

\subsection{Similarity between soil seed bank and standing vegetation}

On REF, a total of 45 species were recorded in the standing vegetation, of which 26 species were also present in the soil seed bank.
Table 5

ANOSIM results for direct comparison of single microsites between the study sites and the overall mean dissimilarity as calculated by SIMPER. CAN = canopy, OBS $=$ obstacle, and BG = bare ground.

\begin{tabular}{llll}
\hline REF vs. DEG & $R$ & $p$ & Mean dissimilarity (\%) \\
\hline CAN vs. CAN & 1 & 0.1001 & 59.9 \\
CAN vs. OBS & 1 & 0.0966 & 69.2 \\
CAN vs. BG & 1 & 0.1046 & 77.5 \\
OBS vs. CAN & 1 & 0.1013 & 70.5 \\
OBS vs. OBS & 1 & 0.1032 & 68.4 \\
OBS vs. BG & 1 & 0.1002 & 72.1 \\
BG vs. CAN & 1 & 0.1060 & 74.1 \\
BG vs. OBS & 1 & 0.0999 & 69.9 \\
BG vs. BG & 1 & 0.0934 & 68.9 \\
\hline
\end{tabular}



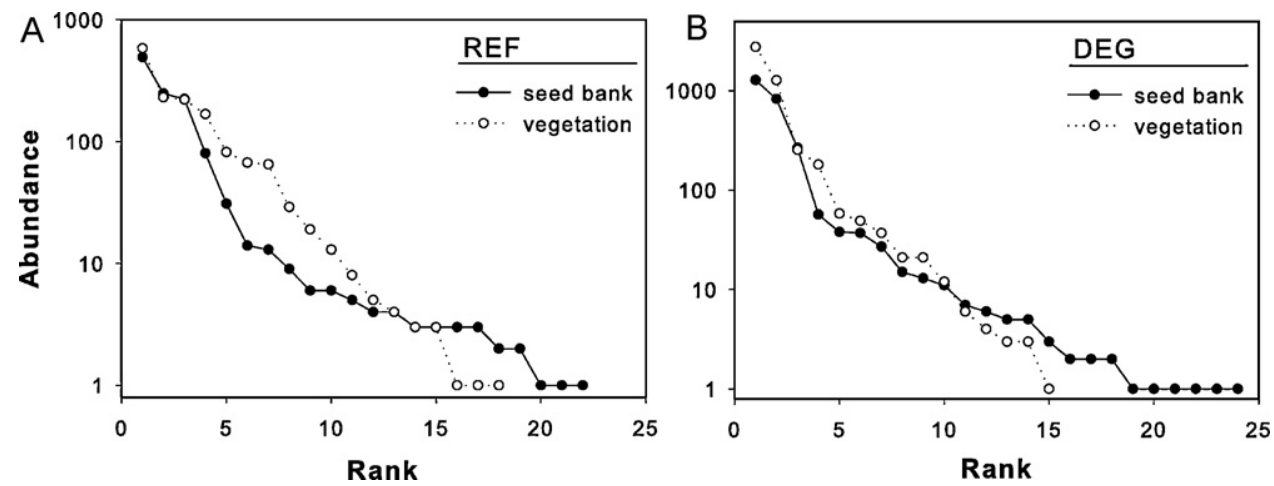

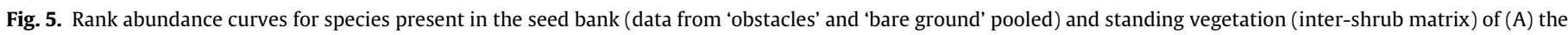
reference site (REF) and (B) the degraded site (DEG).

At DEG, standing vegetation comprised 43 species, and 24 species were common to both vegetation and soil seed bank (Table 1). Under both grazing regimes, the floristic similarity between the vegetation and soil seed bank was moderate (mean Sørensen index: $R E F=53.0 \%, D E G=59.7 \%$; REF vs. DEG: $p=0.36$ ), whereas the inter-shrub matrix was characterized by a high conformity in species-specific abundance patterns regarding the most dominant species (Table 3). At REF, the four most abundant species in the standing vegetation were among the five most abundant seed bank species, comprising three forbs and the perennial grass S. uniplumis. Conformity at DEG was even higher with eight annual species of similar abundance in the soil seed bank and vegetation (Table 3). Accordingly, the shapes of species abundance distributions (SADs) were similar for species assemblages in the vegetation and soil seed bank, in particular on DEG (Fig. 5A and B).

SADs followed a lognormal distribution of species abundances independent of grazing regime with a steep initial slope due to a few species over-represented in both soil seed bank and vegetation (compare Table 1) and with a high proportion of intermediate species. There was a higher proportion of rare species (very low abundances) in the soil seed bank than in the vegetation at DEG (Fig. 5B), and an increased evenness in the rank-abundance pattern of the vegetation at REF compared to the soil seed bank (Fig. 5A).

\section{Discussion}

\subsection{The magnitude of seed bank divergence across the fence-line}

At both study sites, the soil seed bank is shaped by a long grazing history, current grazing impacts and past climatic patterns (Dreber and Esler, 2011). Thus, differences in the soil seed bank are likely to reflect manifested properties rather than short-term changes, providing a good estimate of how far the systems have diverged. Under both grazing regimes, more than $70 \%$ of seed bank species were annuals. As they produce numerous, long-lived seeds as part of their opportunistic strategy, radical divergence in annual species composition and abundance can be seen as evidence for a fairly advanced change in seed bank community.

Seed bank communities at DEG were significantly altered by long-term severe grazing with annuals contributing most to the observed dissimilarity to REF. However, there was quite a large pool of common species ( $72 \%$ for REF, $64 \%$ for DEG), of which the half accounted for $80 \%$ of total dissimilarity. It therefore appears that the divergence of seed bank communities is relatively low at species level, and the overall difference is to be found at abundance level in species-specific responses to grazing intensity. This was illustrated by the switched positions of many species within the species abundance distribution curves. Murray et al. (1999) described such opportunistic species as "somewhere-abundant species", char- acterized by appropriate traits permitting them to increase in abundance given a suitable opportunity. Overall, short-lived, atelechoric species depending on regeneration by seed, dominated the soil seed banks. Accordingly, the annual/biennial life cycle, high abundance of tiny and small diaspores and, consequently, persistent soil seed banks were similarly the most represented plant regenerative strategies irrespective of the grazing regime. However, there was a shift in the abundance of regeneration strategies known to be related to grazing and/or trampling avoidance or tolerance (Aboling et al., 2008; Cornelissen et al., 2003; Navie and Rogers, 1997). Persistence under severe grazing was linked to the trait combination of high seed production, prostrate growth and/or easily buried small and rounded seeds. The dominant annual grasses deter grazing through low palatability during the reproductive phase and possess diaspore appendages favoring epizoochorous dispersal. The valuable perennial fodder grasses at the study sites depend on continuous seed production for the replenishment of their transient seed banks. Severe grazing pressure on seed bearing plants and prolonged droughts therefore are likely drivers of their seed bank depletion (O'Connor and Pickett, 1992; Solomon et al., 2006), giving way for an increase in population size of less-competitive species. Similarly, Aboling et al. (2008) and Sternberg et al. (2003) report a large differential effect of grazing on functional groups in a Mediterranean herbaceous community by selective removal of palatable, large and competitive species in favor of short and prostrate species.

Our results demonstrate that site-specific grazing impacts in the long-term determine the development of local species pools dominated by plant functional groups adapted to low or high grazing pressure. Currently, these pools represent local variations, as the overall species composition remained largely unchanged. It still has to be established whether the detected differences represent community fluctuations within the same ecosystem state or two alternative resilient states (López et al., 2011).

\subsection{Similarity between soil seed bank and standing vegetation}

The detected divergence between seed bank communities across the fence-line was related to the condition of the aboveground herbaceous and grassy vegetation and, contrary to what was hypothesized, a similarly close relationship between seed bank and standing vegetation under both grazing regimes. The moderate floristic similarity agrees with Sørensen indices reported from other arid and semiarid grazing lands under different disturbance intensities in Australia (Kinloch and Friedel, 2005a) and Ethiopia (Kassahun et al., 2009). It reflects a commonly observed trend in unpredictable environments due to a high proportion of annuals compared to perennials in the standing vegetation, their main regeneration by seed, short dispersal distances and long-lived seeds 
(Hopfensperger, 2007). As the local divergence of seed banks relied on species-specific variation in abundance as a function of grazing avoidance rather than compositional changes, the mean Sørensen index between the sites did not differ significantly.

Patterns in species abundance distributions found both in the vegetation and soil seed bank of the inter-shrub matrix were similar and reflect a common pattern in community structure at a local scale with a few very abundant species, a high proportion of intermediate-sized populations and a certain fraction of rare species (Murray et al., 1999; Oldeland et al., 2010). This pattern was maintained even in a highly degraded environment under severe grazing pressure. At species level, abundance patterns in the soil seed bank and standing vegetation were also similar, but this conformity mainly relied on the fraction of annuals. Thus, the subset of species found growing in the inter-shrub matrix, that excludes most of the perennial vegetation, had predictive value for abundance in the persistent seed bank. This supports the findings of Caballero et al. (2008) in semiarid Mediterranean shrublands, where the temporal relationship in abundance of perennials between seed bank and vegetation was weaker than for annuals, as the local persistence of perennials is mainly based on the plant's longevity. Olano et al. (2005) conclude that semiarid seed banks are a good predictor of annual community performance in terms of vegetation composition and cover. This is confirmed by our results.

\subsection{The importance of shrubs for rangeland regeneration}

Grazing-resistant shrubs at DEG like $C$. capitata and $R$. trichotomum accumulate large and diverse soil seed banks beneath their canopy (Dreber and Esler, 2011), which we showed to be different in composition from seed banks of the open matrix. Thus, the shrubs function as effective seed traps and may provide safe sites for certain suppressed species to germinate and establish by providing refuge in the overgrazed environment (Flores and Jurado, 2003). However, the replenishment of seed banks governed by secondary dispersal is provided for local species pools only. As indicated by the dissimilarities of microsites across the fence-line, these processes exclude potential successors in a post-grazing scenario. Thus, the hypothesis of a higher similarity of shrub understorey seed banks at DEG with the reference site compared to microsites of the open matrix has to be rejected. The local lack of desirable propagules such as of perennial grasses can have three possible causes: (a) reduced seed set through grazing livestock, (b) a low amount of seed arriving at the site and/or (c) inadequate seed retention, which is related to the availability of safe sites (Kinloch and Friedel, 2005b; Solomon et al., 2006). The latter was proved not to be a limiting factor (Dreber and Esler, 2011). Therefore, the low amount of seeds of species negatively related to high grazing pressure even in effective seed traps indicates that grazing largely prevents their sexual reproduction and that the arrival of propagules from the adjacent reference site is insufficient. Consequently, for populations, whose seed banks are nearly depleted, long-distance dispersal can be regarded the main limiting factor for local survival and natural re-establishment, respectively (Dutoit and Alard, 1995; Kadmon and Shmida, 1990).

\subsection{Evaluation of the restoration potential}

The documented magnitude of grazing induced changes in the relative abundance of species may indicate a persistent change in vegetation (Solomon et al., 2006). At DEG, long-term heavy goat grazing drastically reduced the seed bank size of many grazingsensitive species. The presence of these soil seed banks suggests that time to potential extinction of respective populations is delayed with a potential increase in size after severe disturbance by livestock (Kalisz and McPeek, 1993; Kinucan and Smeins, 1992; Tracy and Sanderson, 2000). However, (a) the seed-dominance of established grazing resistant annuals with persistent seed banks, (b) the predominating regeneration by seed and (c) restricted dispersal ability make recruitment of suppressed species unlikely to be successful in the short-term even under reduced grazing pressure. Moreover, critical thresholds between vegetation states can be associated with the local extinction of key species relevant for ecosystem functioning (López et al., 2011). At DEG, rangeland improvement depends on the recovery of perennial climax grasses such as S. uniplumis. These grasses are functionally important by preventing soil erosion, enhancing ecohydrological feedback mechanisms and contributing substantially to the grazeable yield (Domptail et al., 2010). Snyman (2004) concludes from the lack of climax grasses in the soil seed bank and their very low abundance in deteriorated vegetation that arid and semiarid rangelands reach a threshold of degradation, beyond which spontaneous recovery over the short-term is excluded. This is linked to sufficient infiltration rates supporting grass establishment (Allington and Valone, 2010), which are, however, reduced by prominent bare patches at DEG that are prone to crusting (Dreber and Esler, 2011).

In arid and semiarid ecosystems, recovery processes in degraded rangelands are slow and stochastic (Call and Roundy, 1991; Visser et al., 2004), and the time span for improvement might last several decades (Allington and Valone, 2010; Wiegand and Milton, 1996), which is beyond what is relevant for management. Both the time needed and the lack of a promising natural restoration potential at DEG to support species which are common to sustainably managed rangelands, point towards the need for active interventions. The maintenance of landscape functionality in terms of trapping and storing seeds (Dreber and Esler, 2011) suggests that interventions improving capture of seeds and natural recruitment like brushpacking (Simons and Allsopp, 2007) are unnecessary at the degraded site. Due to the negligible seed rain effects, for restoration the artificial creation of a seed bed of target species is most important. Seed rich topsoil replacement and sowing of target species (De Villiers et al., 2003; Solomon et al., 2006; Visser et al., 2004) implemented in a long-term strategic framework of sustainable land management (Jones and Esler, 2004) would be necessary in order to improve rangeland condition in terms of vegetation composition, functionality, and productivity. However, the success strongly relies on species-specific recruitment and establishment requirements, which have to be understood in advance (Simons and Allsopp, 2007).

\section{Acknowledgements}

We thank the management of the Gellap-Ost Research Station and the Nuwefontein community for permission to work on their land and support during data collection, K. Baumgärtner of the Botanical Garden at the University of Hamburg for providing assistance during the germination trials, all students and colleagues who contributed to the completion of the study, and two anonymous reviewers for valuable comments on an earlier draft. Funding was provided by the BIOTA Southern Africa project which is sponsored by the German Federal Ministry of Education and Research (BMBF) under promotion number 01 LC 0024A. The Namibian Ministry of Environment and Tourism (MET) kindly granted a research permit.

Role of the funding source: BMBF provided funding but played no role in the design and execution of this study and in article preparation.

\section{References}

Aboling, S., Sternberg, M., Perevolotsky, A., Kigel, J., 2008. Effects of cattle grazing timing and intensity on soil seed banks and regeneration strategies in a Mediterranean grassland. Commun. Ecol. 9, 97-106.

Allington, G.R.H., Valone, T.J., 2010. Reversal of desertification: the role of physical and chemical soil properties. J. Arid Environ. 74, 973-977. 
Beukes, P.C., Cowling, R.M., Higgins, S.I., 2002. An ecological economic simulation model of a non-selective grazing system in the Nama Karoo, South Africa. Ecol. Econ. 42, 221-242.

Briske, D.D., Bestelmeyer, B.T., Stringham, T.K., Shaver, P.L., 2008. Recommendations for development of resilience-based State-and-Transition models. Rangel. Ecol. Manag. 61, 359-367.

Caballero, I., Olano, J.M., Loidi, J., Escudero, A., 2008. A model for small-scale seed bank and standing vegetation connection along time. Oikos 117, 1788-1795.

Call, C.A., Roundy, B.A., 1991. Perspectives and processes in revegetation of arid and semiarid rangelands. Rangel. Ecol. Manag. 44, 543-549.

Chambers, J.C., MacMahon, J.A., Haefner, J.H., 1991. Seed entrapment in alpine ecosystems: effects of soil particle size and diaspore morphology. Ecology 72, 1668-1677.

Clarke, K.R., 1993. Non-parametric multivariate analyses of changes in community structure. Austral Ecol. 18, 117-143.

Clarke, K.R., Gorley, R.N., 2006. Primer v6: User Manual/Tutorial. Primer-E Ltd., Plymouth, UK.

Cornelissen, J.H.C., Lavorel, S., Garnier, E., Diaz, S., Buchmann, N., Gurvich, D.E., Reich, P.B., Ter Steege, H., Morgan, H.D., Van der Heijden, M.G.A., Pausas, J.G., Poorter, H., 2003. A handbook of protocols for standardized and easy measurement of plant functional traits worldwide. Aust. J. Bot. 51, 335-380.

Darkoh, M.B.K., 2009. An overview of environmental issues in Southern Africa. Afr. J. Ecol. 47, 93-98.

Dean, W.R.J., Hoffman, M.T., Meadows, M.E., Milton, S.J., 1995a. Desertification in the semi-arid Karoo, South Africa: review and reassessment. J. Arid Environ. 30, 247-264.

Dean, W.R.J., Milton, S.J., du Plessis, M.A., 1995b. Where, why, and to what extent have rangelands in the Karoo, South Africa, desertified. Environ. Monit. Assess. 37, 103-110.

De Villiers, A.J., Van Rooyen, M.W., Theron, G.K., 2003. Similarity between the soil seed bank and the standing vegetation in the Strandveld Succulent Karoo, South Africa. Land Degrad. Dev, 14, 527-540.

Domptail, S.E., Dreber, N., Falk, T., Gibreel, T., Kirk, M., Limpricht, C., Naumann, C. Prediger, S., Vollan, B., Wesuls, D., 2010. An ecological-economic analysis of the pastoral systems of the Nama Karoo in southern Namibia. In: Hoffman, M.T. Schmiedel, U., Jürgens, N. (Eds.), Biodiversity in Southern Africa. Volume 3: Implications for Landuse and Management. Klaus Hess Publishers, Göttingen and Windhoek.

Dreber, N., Esler, K.J., 2011. Spatio-temporal variation in soil seed banks under contrasting grazing regimes following low and high seasonal rainfall in arid Namibia. J. Arid Environ. 75, 174-184.

Dutoit, T. Alard, D. 1995. Permanent seed banks in chalk grassland under various management regimes: their role in the restoration of species-rich plan communities. Biodivers. Conserv. 4, 939-950.

Esler, K.J., 1999. Plant reproductive ecology. In: Dean, W.R.J., Milton, S.J. (Eds.), The Karoo. Ecological Patterns and Processes. University Press, Cambridge.

Flores, J., Jurado, E., 2003. Are nurse-protégé interactions more common among plants from arid environments? J. Veg. Sci. 14, 911-916.

Germishuizen, G., Meyer, N.L., 2003. Plants of Southern Africa: An Annotated Checklist. Strelitzia 14. National Botanical Institute, Pretoria.

Hammer, Ø., Harper, D.A.T., Ryan, P.D., 2001. PAST: Paleontological Statistics software package for education and data analysis. Palaeontol. Electron. 4, http://palaeo-electronica.org/2001_1/past/issue1_01.htm.

Hartnett, D.C., Setshogo, M.P., Dalgleish, H.J., 2006. Bud banks of perennial savanna grasses in Botswana. Afr. J. Ecol. 44, 256-263.

Hopfensperger, K.N., 2007. A review of similarity between seed bank and standing vegetation across ecosystems. Oikos 116, 1438-1448.

Jones, F.E., Esler, K.J., 2004. Relationship between soil-stored seed banks and degradation in eastern Nama Karoo rangelands (South Africa). Biodivers. Conserv. 13 2027-2053.

Kadmon, R., Shmida, A., 1990. Spatiotemporal demographic processes in plant populations: an approach and a case study. Am. Nat. 135, 382-397.

Kalisz, S., McPeek, M.A., 1993. Extinction dynamics, population growth and seed banks. An example using an age-structured annual. Oecologia 95, 314-320.

Kassahun, A., Snyman, H.A., Smit, G.N., 2009. Soil seed bank evaluation along a degradation gradient in arid rangelands of the Somali region, eastern Ethiopia. Agric. Ecosyst. Environ. 129, 428-436.
Kinloch, J.E., Friedel, M.H., 2005a. Soil seed reserves in arid grazing lands of central Australia. Part 1. Seed bank and vegetation dynamics. J. Arid Environ. 60, 133-161.

Kinloch, J.E., Friedel, M.H., 2005b. Soil seed reserves in arid grazing lands of centra Australia. Part 2. Availability of "safe sites". J. Arid Environ. 60, 163-185.

Kinucan, R.J., Smeins, F.E., 1992. Soil seed bank of a semiarid Texas grassland under three long-term (36-years) grazing regimes. Am. Midl. Nat. 128, 11-21.

Klintenberg, P., Seely, M., 2004. Land degradation monitoring in Namibia: a first approximation. Environ. Monit. Assess. 99, 5-21.

Kuiper, S.M., Meadows, M.E., 2002. Sustainability of livestock farming in the communal lands of southern Namibia. Land Degrad. Dev. 13, 1-15.

López, D.R., Cavallero, L., Brizuela, M.A., Aguiar, M.R., 2011. Ecosystemic structural-functional approach of the state and transition model. Appl. Veg. Sci. 14, 6-16.

Meissner, R.A., Facelli, J.M., 1999. Effects of sheep exclusion on the soil seed bank and annual vegetation in chenopod shrublands of South Australia. J. Arid Environ. 42, 117-128.

Mendelsohn, J., Jarvis, A., Roberts, C., Robertson, T., 2002. Atlas of Namibia. A Portrait of the Land and its People. David Philip Publishers, Cape Town.

Müller, B., Frank, K., Wissel, C., 2007. Relevance of rest periods in non-equilibrium rangeland systems-a modelling analysis. Agric. Syst. 92, 295-317.

Murray, B.R., Rice, B.L., Keith, D.A., Myerscough, P.J., Howell, J., Floyd, A.G., Mills, K., Westoby, M., 1999. Species in the tail of rank-abundance curves. Ecology 80 1806-1816.

Navie, S.C., Rogers, R.W., 1997. The relationship between attributes of plants represented in the germinable seed bank and stocking pressure in a semi-arid subtropical rangeland. Aust. J. Bot. 45, 1055-1071.

O'Connor, T.G., 1991. Local extinction in perennial grasslands: a life-history approach. Am. Nat. 137, 753-773.

O'Connor, T.G., Pickett, G.A., 1992. The influence of grazing on seed production and seed banks of some African savanna grasslands. J. Appl. Ecol. 29, 247-260.

Olano, J.M., Caballero, I., Loidi, J., Escudero, A., 2005. Prediction of plant cover from seed bank analysis in a semi-arid plant community on gypsum. J. Veg. Sci. 16 215-222.

Oldeland, J., Dreber, N., Wesuls, D., 2010. Diversity measures in comparative rangeland studies: application and advantages of species abundance distributions and diversity profiles. Dinteria 31, 50-66.

Simons, L., Allsopp, N., 2007. Rehabilitation of rangelands in Paulshoek, Namaqualand: understanding vegetation change using biophysical manipulations. J. Arid Environ. 70, 755-766

Snyman, H.A., 1998. Dynamics and sustainable utilization of rangeland ecosystems in arid and semi-arid climates of southern Africa. J. Arid Environ. 39, 645666.

Snyman, H.A., 2004. Soil seed bank evaluation and seedling establishment along a degradation gradient in a semi-arid rangeland. Afr. J. Range For. Sci. 21, 37-

Solomon, T.B., Snyman, H.A., Smit, G.N., 2006. Soil seed bank characteristics in relation to land use systems and distance from water in a semi-arid rangeland of southern Ethiopia. S. Afr. J. Bot. 72, 263-271.

Sternberg, M., Gutman, M., Perevolotsky, A., Kigel, J., 2003. Effects of grazing on soil seed bank dynamics: an approach with functional groups. J. Veg. Sci. 14 375-386.

Todd, S.W., Hoffman, M.T., 2009. A fence line in time demonstrates grazing-induced vegetation shifts and dynamics in the semiarid Succulent Karoo. Ecol. Appl. 19, 1897-1908

Tracy, B.F., Sanderson, M.A., 2000. Seedbank diversity in grazing lands of the Northeast United States. Rangel. Ecol. Manag. 53, 114-118.

Visser, N., Botha, J.C., Hardy, M.B., 2004. Re-establishing vegetation on bare patches in the Nama Karoo, South Africa. J. Arid Environ. 57, 155-177.

Ward, D., Ngairorue, B.T., Karamata, J., Kapofi, I., Samuels, R., Ofran, Y., 2000. Effects of communal pastoralism on vegetation and soil in a semi-arid and in an arid region of Namibia. In: Proceedings of the IAVS Symp. , pp. 344-347.

Ward, D., Ngairorue, B.T., Kathena, J., Samuels, R., Ofran, Y., 1998. Land degradation is not a necessary outcome of communal pastoralism in arid Namibia. J. Arid Environ. 40, 357-371.

Wiegand, T., Milton, S.J., 1996. Vegetation change in semiarid communities. Simulating probabilities and time scales. Plant Ecol. 125, 169-183. 